\title{
Atividade vasodilatadora in vitro de espécies de Ouratea (Ochnaceae) e de frações de Ouratea Semiserrata (Mart.) Engl.
}

\author{
Ydia Mariele Valadares', Alaíde Braga de Oliveira1', Steyner F. Côrtes², Júlio Antônio Lombardi³, \\ Fernão Castro Braga ${ }^{1 *}$
}

'Faculdade de Farmácia, Universidade Federal de Minas Gerais, 2Departamento de Farmacologia, Instituto de Ciências Biológicas, Universidade Federal de Minas Gerais, ${ }^{3}$ Departamento de Botânica, Instituto de Ciências Biológicas, Universidade Federal de Minas Gerais

*Correspondência:

F. C. Braga

Faculdade de Farmácia

Universidade Federal de Minas Gerais

Av. Olegário Maciel, 2360

30.180-112 - Belo Horizonte - MG

Brasil

E-mail: fernao@dedalus.lcc.ufmg.br
Diversas espécies de Ouratea ocorrem no cerrado, sendo utilizadas popularmente como tônico, adstringente e antiinflamatório. No presente trabalho, os extratos hidroetanólicos de O. castanaefolia, $\mathrm{O}$. spectabilis $e \mathrm{O}$. semiserrata foram avaliados para atividade vasodilatadora em anéis de aorta pré-contraídos com fenilefrina. Apenas o extrato de caules de O. semiserrata (OS) produziu vasodilatação significativa ( $63 \pm 3 \%, n=6)$, na concentração de $100 \mathrm{mg} / \mathrm{mL}$. O fracionamento biomonitorado de OS resultou em uma fração enriquecida em proantocinanidinas, que produziu 100 $\pm 5 \%$ de vasodilatação $(n=6)$, na concentração de $100 \mathrm{mg} / \mathrm{mL}$. Os teores totais de proantocianidinas foram determinados para OS e para as frações bioativas, por espectroscopia no visivel. Maiores teores de proantocianidinas implicaram aumento da atividade vasodilatadora $\left(r^{2}=0,9760\right)$, sugerindo que compostos desta classe devem ser responsáveis pela atividade do extrato de caules de $\mathrm{O}$. semiserrata.
Unitermos:

- Ouratea semiserrata

- Ouratea castanaefolia

- Ouratea spectabilis

- Efeito vasodilatador

- Anéis de aorta

- Teor total de proantocianidinas

\section{INTRODUÇÃO}

Ouratea semiserrata (Mart.) Engl. (Ochnaceae) é uma espécie arbustiva, ocorrente no cerrado. O extrato dos caules desta espécie apresentou atividade inibitória in vitro da enzima conversora de angiotensina, sugerindo potencial atividade anti-hipertensiva (Braga et al., 2000).

Nenhuma descrição foi encontrada sobre o uso popular de O. semiserrata no Brasil. Outras espécies de Ouratea, no entanto, são utilizadas popularmente como tônico e adstringente $(O$. castanaefolia, $O$. parviflora), como antiinflamatório e em doenças da pele (O. parviflora) e, também, para tratar doenças gástricas (O. spectabilis) (Corrêa, 1975; Paulo et al., 1986; Felício et al., 1995). Não foram encontrados relatos sobre o uso tradicional de Ouratea spp. como anti-hipertensivo ou diurético.

A química do gênero Ouratea (Ochnaceae) ainda é pouco conhecida. O estudo fitoquímico das folhas de $O$. semiserrata levou ao isolamento do ácido ent-16 $\alpha, 17 \beta$ diidroxicauran-19-óico (1) (Velandia et al., 1998) e, da madeira desta espécie, foram isoladas duas isoflavonas cloradas, 6,8,3'-tricloro-4',5-diidroxi-7-metoxiisoflavona (2) e 6,8,3',5'-tetracloro-4',5-diidroxi-7-metoxiisoflavona (3) (Velandia et al., 1998). Amentoflavona (4) e 3-hidroxi- 


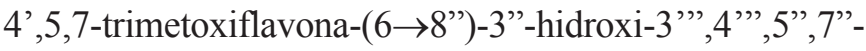
tetrametoxiflavona (5), um composto inédito, foram isoladas das folhas de $O$. multiflora (Felício et al., 2001). Das raízes de Ouratea sp. foram isoladas a $3,5,7,3^{\prime}, 5^{\prime}$ pentaidroxi-4'-metoxi-epi-catequina (6) e duas proantocianidinas diméricas denominadas ouratea proantocianidina A (7) e ouratea proantocianidina B (8) (Delle Monache et al., 1967; Delle Monache et al., 1970). Das folhas de $O$. spectabilis foram isoladas as biflavonas 6,6'bigenkvanina (9) e 7,7'-dimetoxigatisflavona (10), esta última apresentando atividade inibitória in vitro da aldose redutase (Felício et al., 1995). Dímeros de isoflavonas denominados hexaspermona A (11), B (12) e C (13) foram obtidos das raízes de $O$. hexasperma (Moreira et al., 1994), sendo um deles ativo in vitro contra linhagens celulares de Sarcoma 180 apresentando, também, atividade in vivo frente ao mesmo tumor implantado em camundongos (Grynberg et al., 1994).

Produtos naturais de diversas classes apresentam atividade vasodilatadora in vitro, incluindo flavonóides, proantocianidinas e alcalóides (Ambriambeloson et al., 1998; Herrera et al., 1996; Freitas et al., 1996). Destes, as proantocianidinas são os compostos mais ativos, apresentando $\mathrm{IC}_{50}$ entre 1-10 mM/L (Ambriambeloson et al., 1998). No presente trabalho, relata-se a triagem de três espécies de Ouratea para atividade vasodilatadora em anéis de aorta e o fracionamento biomonitorado do extrato de caules de $O$. semiserrata, utilizando-se o mesmo modelo. Buscou-se, ainda, correlacionar a atividade vasodilatadora com o teor de proantocianidinas totais, determinado para o extrato e as frações ativas.

\section{MATERIAIS E MÉTODOS}

\section{Material vegetal}

Amostras de caules e folhas de Ouratea castanaefolia Engl., Ouratea spectabilis (Mart.) Engl. e Ouratea semiserrata (Mart.) Engl. foram coletadas em Minas Gerais, respectivamente no campus da UFMG, Belo Horizonte (08/99), em Perdizes (09/99) e na Serra do Cipó (10/99). A coleta e identificação do material vegetal foram realizadas pelo Prof. Júlio Antônio Lombardi, do Departamento de Botânica, ICB, UFMG. Exsicatas das espécies foram depositadas no herbário do ICB/UFMG, sob números 50394, 48940 e 49269 , respectivamente.

\section{Preparação dos extratos}

O material vegetal (caules e folhas) foi lavado em água corrente e seco, separadamente, em estufa ventilada, a $40{ }^{\circ} \mathrm{C}$, por 72 horas. Após a moagem, em moinho de facas, os materiais vegetais pulverizados foram extraídos por percolação exaustiva com EtOH 96\%, seguindo-se secagem até resíduo, em evaporador rotatório, a $70^{\circ} \mathrm{C}$. As massas dos materiais vegetais utilizadas e os extrativos obtidos estão listados na Tabela I.

TABELA I - Massas de materiais vegetais secos e extrativos obtidos por percolação exaustiva com EtOH 96\%, para espécies de Ouratea em estudo

\begin{tabular}{lcccc}
\hline Espécie & \multicolumn{2}{c}{ Material Vegetal (g) } & \multicolumn{2}{c}{ Extrativos (\%) } \\
& Folha & Caule & Folha & Caule \\
\hline O. castanaefolia & 313,5 & 590,0 & 17,7 & 13,4 \\
O. spectabilis & 172,9 & 668,6 & 36,6 & 36,3 \\
O. semiserrata & 205,3 & 699,7 & 30,1 & 13,5 \\
\hline
\end{tabular}

\section{Fracionamento do extrato de $\boldsymbol{O}$. semiserrata}

Alíquotas $(5,0 \mathrm{~g})$ do extrato seco de caules de $O$. semiserrata foram solubilizadas em água $\left(100 \mathrm{~mL}, 50^{\circ} \mathrm{C}\right)$, sob agitação. A solução obtida foi transferida para funil de separação e submetida a partições sucessivas com $n$ hexano $(3 \times 100 \mathrm{~mL})$, acetato de etila $(3 \times 100 \mathrm{~mL})$ e $n$ butanol $(3 \times 100 \mathrm{~mL})$. Os solventes foram removidos em evaporador rotatório, à temperatura máxima de $70^{\circ} \mathrm{C}$. Os resíduos obtidos foram mantidos em dessecador, sob vácuo, ao abrigo da luz. Este procedimento foi repetido nove vezes para se obter massa suficiente para os ensaios biológicos e fracionamento posterior, no caso da fração acetato de etila (massa do resíduo obtido para a fração EtOAc: $580 \pm 113 \mathrm{mg}, n=9$ ).

\section{Separação cromatográfica da fração acetato de etila}

Uma alíquota da fração acetato de etila $(2,0 \mathrm{~g})$ foi cromatografada em coluna de sílica-gel 60 (70-230 mesh, Merck; 680 x $30 \mathrm{~mm}$ d.i) utilizando-se solventes de polaridade crescente: $\mathrm{Ac} 1, n$-hexano: $\mathrm{CH}_{2} \mathrm{Cl}_{2}(1: 1,950 \mathrm{~mL})$; $\mathrm{Ac} 2, \mathrm{CH}_{2} \mathrm{Cl}_{2}(350 \mathrm{~mL}) ; \mathrm{Ac} 3, \mathrm{CH}_{2} \mathrm{Cl}_{2}: \mathrm{CHCl}_{3}(1: 1,525$ $\mathrm{mL}) ; \mathrm{Ac}_{4}, \mathrm{CHCl}_{3}(450 \mathrm{~mL}) ; \mathrm{Ac} 5, \mathrm{CHCl}_{3}:$ EtOAc $(3: 1,775$ $\mathrm{mL})$; Ac6, $\mathrm{CHCl}_{3}$ : EtOAc (1:1, $\left.325 \mathrm{~mL}\right)$; $\mathrm{Ac} 7-9, \mathrm{CHCl}_{3}$ : EtOAc (1:3, $1250 \mathrm{~mL})$; Ac10-11, EtOAc (1285 mL); Ac12-13, EtOAc:MeOH (1:1, $700 \mathrm{~mL})$ e Ac14, MeOH (200 mL). Na seqüência, uma alíquota de Ac12 (343 mg) foi fracionada por cromatografia em contracorrente de alta velocidade (HSCC). O equipamento era composto de rotor P.C MK II CCC (EUA), bomba Shimadzu LC-8 ${ }^{\mathrm{A}}$ (Japão) e sistema controlador Shimadzu SCL-8 ${ }^{\mathrm{A}}$ (Japão). Mistura de clorofórmio:metanol:água $(7: 13: 8)$ foi utiliza- 


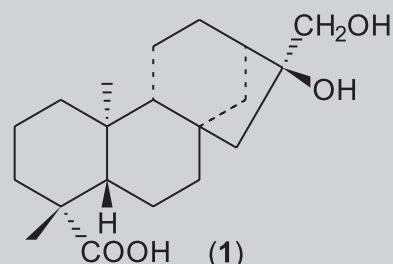

(1)<smiles>COc1cc(O)c2c(=O)cc(-c3ccc(O)cc3)oc2c1-c1c(O)cc2oc(-c3ccc(O)cc3)cc(=O)c2c1O</smiles>

(4)<smiles>COc1c(O)cc([C@@H]2Oc3cc(O)cc(O)c3CC2O)cc1O</smiles>

(6)<smiles>COc1c(O)cc([C@@H]2Oc3c(c(O)cc(O)c3C3c4c(O)cc(O)cc4O[C@H](c4ccc(O)cc4)C3O)CC2O)cc1O</smiles><smiles>COc1cc2oc(-c3ccc(O)cc3)cc(=O)c2c(O)c1-c1c(OC)cc(O)c2c(=O)cc(-c3ccc(O)cc3)oc12</smiles>

(10)<smiles>[R]c1cc(-c2coc3c(Cl)c(OC)c(Cl)c(O)c3c2=O)cc(Cl)c1O</smiles><smiles>COc1ccc(-c2oc3cc(OC)c(-c4c(OC)cc(CO)c5c(=O)c(O)c(-c6ccc(OC)c(OC)c6)oc45)c(OC)c3c(=O)c2O)cc1</smiles>

(5)<smiles>COc1c(O)cc(C2Oc3c(c(O)cc(O)c3C3c4c(O)cc(O)cc4O[C@H](c4ccc(O)cc4)C3O)CC2O)cc1O</smiles>

(7)<smiles>COc1cc2oc(-c3ccc(O)cc3)cc(=O)c2c(O)c1-c1c(OC)cc2oc(-c3ccc(O)cc3)cc(=O)c2c1O</smiles>

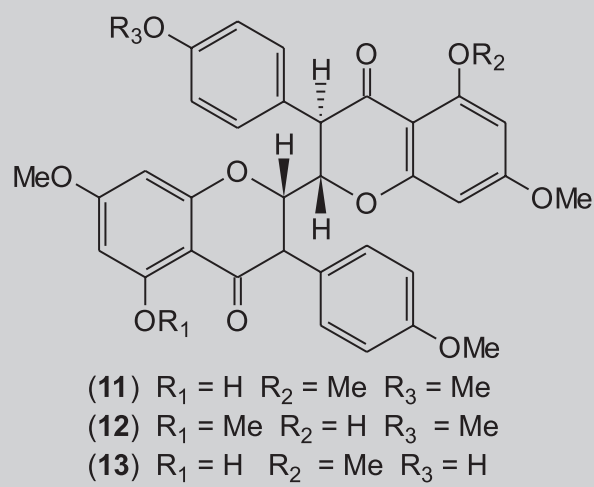

FIGURA 1 - Estruturas químicas de substâncias isoladas de espécies de Ouratea. 
da como sistema de solventes bifásico. A eluição processou-se em fase normal, com fluxo de $1 \mathrm{~mL} / \mathrm{min}$ e rotação de 750 r.p.m. Foram coletadas 70 frações $(10 \mathrm{~mL} /$ fração $)$, reunidas em quatro grupos segundo seus perfis cromatográficos obtidos por HPLC. Após a coleta das 70 frações, a fase estacionária foi removida e concentrada até resíduo, constituindo a fração G-5 (292 mg). O esquema de fracionamento do extrato de $O$. semiserrata está representado no fluxograma da Figura 2.

\section{Análises por HPLC}

As análises foram realizadas em equipamento Merck-Hitachi (Alemanha) composto de bomba L6200A, injetor automático AS-2000A, detector UV-VIS L-4250 e integrador D-2500. Utilizou-se uma coluna de ODS ( 250 x 4,0 mm d.i., $5 \mathrm{~mm}$, Merck, Alemanha) fluxo de $1,0 \mathrm{~mL} / \mathrm{min}$, temperatura de $40{ }^{\circ} \mathrm{C}$, procedendo-se a eluição com gradiente linear de $\mathrm{H}_{2} \mathrm{O}(\mathrm{A})$ e $\mathrm{CH}_{3} \mathrm{CN}(\mathrm{B}): 0$ $\min 90 \% \mathrm{~A}, 10 \% \mathrm{~B} ; 60 \min 10 \% \mathrm{~A}, 90 \% \mathrm{~B}$, seguido de 5 min de eluição isocrática. A detecção foi realizada no UV a $220 \mathrm{~nm}$. Foram utilizados solventes grau HPLC (Merck, Alemanha) e a remoção do ar foi realizada por sonificação. Para as análises, as amostras foram dissolvidas em $\mathrm{MeOH}$ para concentrações de $10 \mathrm{mg} / \mathrm{mL}$ e $5 \mathrm{mg} / \mathrm{mL}$, respectivamente, para extratos e frações, sendo as soluções centrifugadas a $10.000 \mathrm{rpm}$, durante $10 \mathrm{~min}$, previamen- te à injeção. Alíquotas destas soluções $(5 \mathrm{~mL})$ foram injetadas de modo automático.

\section{Determinação do teor total de proantocianidinas}

O teor total de proantocianidinas foi quantificado nos extratos das três espécies e nas frações de $O$. semiserrata, após solvólise catalizada por ácido com $n$ $\mathrm{BuOH} / \mathrm{HCl} 37 \%$ (95:5), segundo metodologia previamente descrita (Hiermann et al., 1986). Procedeu-se à leitura da absorvância da solução a $540 \mathrm{~nm}$, sendo os valores expressos como cloreto de cianidina. Os resultados correspondem à média de três determinações, seguidos dos desvios-padrão.

\section{Análise Estatística}

Os teores totais de proantocianidinas e as percentagens de vasodilatação produzidas pelo extrato e frações de $O$. semiserrata foram submetidos a análise de regressão linear, usando o programa Sigma Plot (Jandel Co., EUA).

\section{Animais}

Ratos Wistar machos (300-350 g) foram utilizados em todos os experimentos. Os animais foram criados em

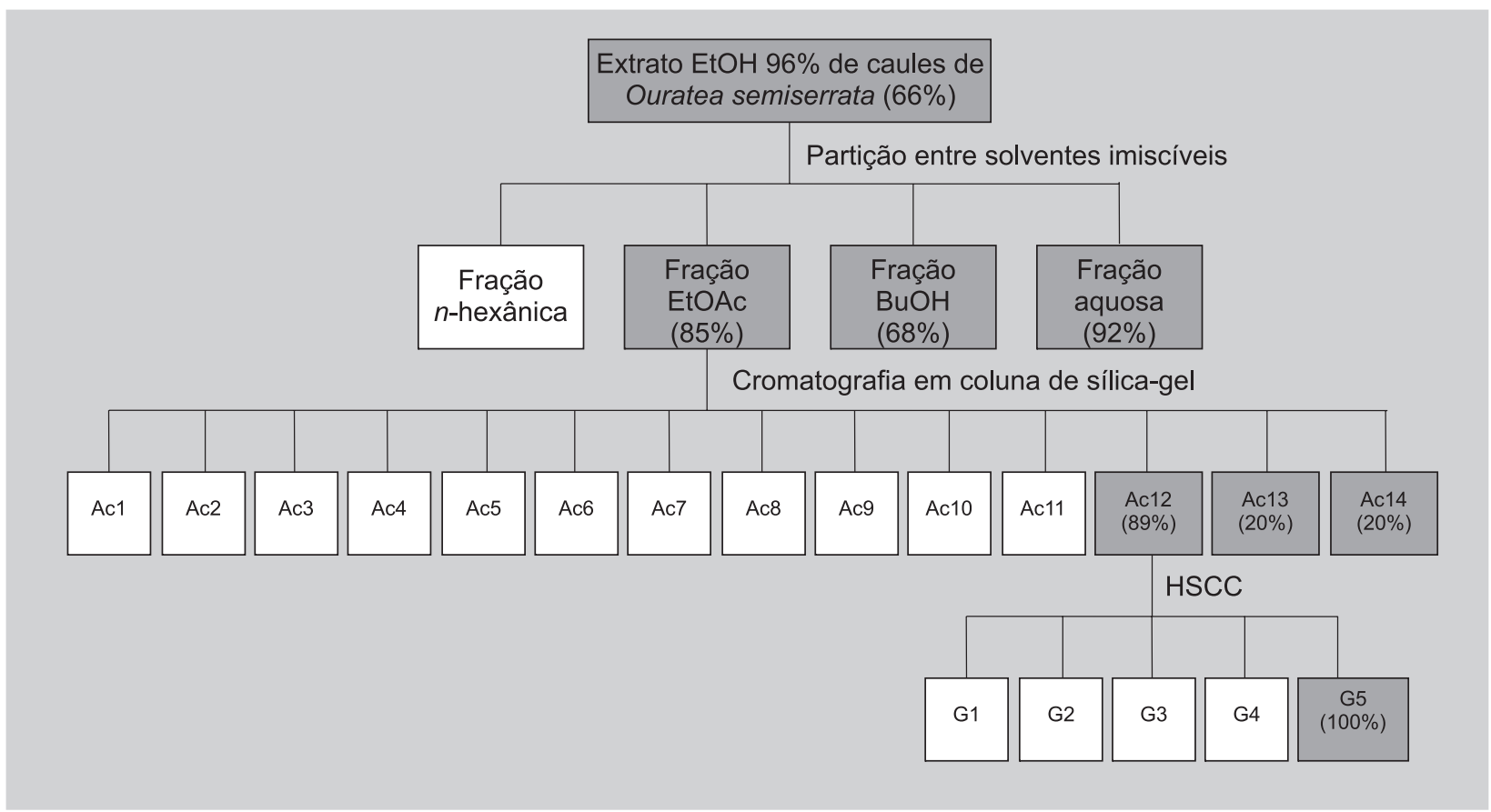

FIGURA 2 - Fracionamento biomonitorado do extrato hidroalcóolico de caules de Ouratea semiserrata. Em destaque aparecem as frações ativas, com os respectivos percentuais de relaxação. 
condições controladas de temperatura $\left(21 \pm 1^{\circ} \mathrm{C}\right)$ e expostos a períodos de luz e penumbra $(12-12 \mathrm{~h})$.

\section{Preparação de anéis de aorta}

Os animais foram sacrificados por deslocamento cervical. A aorta torácica foi rapidamente dissecada e os excessos de gordura e tecido conectivo foram retirados. A seguir, a aorta foi separada em anéis (2-4 $\mathrm{mm}$ de comprimento) e estes foram suspendidos em hastes de aço, nas quais aplicou-se tensão de $1 \mathrm{~g}$. Os anéis foram mantidos em banho de solução isotônica de Krebs-Henseleit e carbogênio $\left(\mathrm{O}_{2} 95 \%, \mathrm{CO}_{2} 5 \%\right)$, a uma temperatura de $37^{\circ} \mathrm{C}$.

\section{Atividade vasodilatadora em anéis de aorta}

Os anéis foram mantidos nas condições descritas acima, atingindo o equilíbrio em 1 hora. A cada $15 \mathrm{~min}$ realizou-se troca da solução fisiológica (composição mM: $\mathrm{NaCL} 110,88 ; \mathrm{KCl} 5,90 ; \mathrm{NaHCO}_{3} 25,00 ; \mathrm{MgSO}_{4} .7 \mathrm{H} 2 \mathrm{O}$ 1,$07 ; \mathrm{CaCl}_{2} \cdot 2 \mathrm{H}_{2} \mathrm{O} 2,49 ; \mathrm{NaH}_{2} \mathrm{PO}_{4} \cdot \mathrm{H}_{2} \mathrm{O} 2,33$ e glicose 11,51). A presença de endotélio funcional foi confirmada por vasodilatação superior a $50 \%$, após administração de acetilcolina $(1 \mathrm{mM})$ a anéis pré-contraídos com fenilefrina $(0,3 \mathrm{mM})$.

Para a execução dos testes, o extrato e as frações foram solubilizados/suspendidos em água e adicionados às preparações previamente contraídas com fenilefrina $(0,3 \mathrm{mM})$, correspondendo a concentração final no banho de $100 \mathrm{mg} / \mathrm{mL}$. Após a adição de cada amostra, aguardouse período de 30 min a fim de que as preparações atingissem novamente o equilíbrio para, então, serem realizados novos testes. As preparações controle foram submetidas, simultaneamente, aos mesmos procedimentos. A vasodilatação foi medida comparativamente à resposta vasodilatadora produzida pela acetilcolina $(1 \mathrm{mM})$. Para a triagem inicial dos extratos das três espécies foram realizados experimentos únicos. No caso de extratos e frações ativas (vasodilatação superior a 50\%) os ensaios foram realizados, no mínimo, em triplicata.

\section{RESULTADOS E DISCUSSÃO}

Dentre as três espécies de Ouratea avaliadas em anéis de aorta pré-contraídos com fenilefrina, apenas o extrato hidroalcóolico de caules de $O$. semiserrata produziu vasodilatação significativa $(63 \pm 3 \%, n=6$, Tabela II), na concentração de $100 \mathrm{mg} / \mathrm{mL}$.

Este resultado demonstra que a espécie em estudo apresenta um efeito vasodilatador marcante no modelo utilizado, em relação a alguns relatados para outros extratos e frações, em que foi empregado o mesmo modelo. O extrato das partes aéreas de Waltheria viscosissima (Sterculiaceae) produziu 75\% de vasodilatação, na concentração de $200 \mathrm{mg} / \mathrm{mL}$ (Vasques, et al., 1999) e os extratos de Chamguava gentlei, Alseis yucatanensis, Licaria peeckii e Nectandra salicifolia produziram vasodilatações de $81,7 \% ; 103,6 \% ; 114,1 \%$ e $68,3 \%$, respectivamente, na concentração de $300 \mathrm{mg} / \mathrm{mL}$ (Slish et al., 1999). Frações enriquecidas em proantocianidinas oligoméricas, obtidas de vinho tinto, apresentaram atividade vasodilatadora de 57 a 77\%, no mesmo modelo, na concentração de $300 \mathrm{mg} / \mathrm{mL}$ (Andriambeloson et al, 1998). Cabe ressaltar que, para os ensaios relatados nesses estudos, foram utilizadas concentrações correspondentes a duas ou três vezes àquelas empregadas no presente trabalho, observando-se,

TABELA II - Atividade vasodilatadora in vitro e teor total de proantocianidinas em extratos hidroalcóolicos de espécies de Ouratea

\begin{tabular}{lccc}
\hline Espécie Vegetal & Parte da planta & Vasodilatação (\%) & *Teor de proantocianidinas (\%) \\
\hline Ouratea castanaefolia & caule & 34 & $2,55 \pm 0,17$ \\
Ouratea semiserrata & folha & SE & $1,32 \pm 0,49$ \\
& caule & $66 \pm 3$ & $6,49 \pm 0,40$ \\
Ouratea spectabilis & folha & SE & $6,63 \pm 0,45$ \\
& caule & SE & $8,70 \pm 0,48$ \\
& folha & SE & $9,99 \pm 0,16$ \\
\hline
\end{tabular}

Nota: todos os extratos foram testados na concentração de $100 \mathrm{mg} / \mathrm{mL}$. SE: sem efeito. Ausência de vasodilatação na concentração ensaiada. Resultados de experimentos únicos, à exceção de caules de $O$. semiserrata (média \pm desviopadrão, $n=6$ ).

*Teores expressos como cloreto de cianidina. Os resultados correspondem à média de três determinações, seguidos dos desvios-padrão. 
para algumas das espécies, percentuais de vasodilatação próximos àquele do extrato de $O$. semiserrata. No presente trabalho, os extratos e frações foram ensaiados na concentração máxima de $100 \mathrm{mg} / \mathrm{mL}$, para evitar efeitos inespecíficos relacionados a altas concentrações.

A prospecção fitoquímica, realizada para folhas e caules das três espécies em estudo, indicou a presença de flavonóides, polifenóis, triterpenos e esteróides em todas elas. Foram obtidos perfis cromatográficos por HPLC para os extratos das espécies em estudo. De maneira geral, todos os cromatogramas indicaram composições complexas, sendo que, para os extratos de caules, observaram-se maiores números de picos em relação aos extratos de folhas (Figura 3).

Os perfis cromatográficos sugeriram, também, maior semelhança na composição dos extratos de folhas de $O$. spectabilis e $O$. semiserrata. No caso dos extratos de caules, $O$. semiserrata e $O$. castanaefolia apresentaram composição química mais próxima (Figura 3). Apesar da semelhança entre esses dois extratos, a vasodilatação produzida pelos caules de $O$. semiserrata foi consideravelmente maior do que aquela observada para $O$. castanaefolia $(\mathrm{Ta}-$ bela II).

Tendo em vista que proantocianidinas possuem atividade vasodilatadora in vitro (Ambriambeloson et al., 1998; Packer et al., 1999) e que substâncias desta classe já foram anteriormente isoladas de espécies de Ouratea, é possível que elas sejam os constituintes ativos de $O$. semiserrata. Assim, procedeu-se à determinação espectrofotométrica do teor total de proantocianidinas nos extratos das espécies em estudo (Tabela II), segundo metodologia descrita por Hiermann e colaboradores (1986).

Não se observou diferença significativa entre os teores determinados para os extratos de caules e folhas de $O$. semiserrata $(\mathrm{p}<0,05)$, sendo estes valores intermediários em relação àqueles determinados para as demais espécies. Os extratos de O. spectabilis, apesar de apresentarem os maiores teores de proantocianidinas, não produziram vasodilatação no modelo utilizado. Estes resultados sugerem que o extrato de caules de $O$. semiserrata deve apresentar proantocianidinas estruturalmente distintas daquelas presentes nos demais extratos. Andriambeloson e colaboradores (1998) sugeriram que o grau de polimerização de taninos condensados desempenha papel importante na atividade vasodilatadora. Ao estudarem frações obtidas de vinho tinto, os autores observaram que aquelas enriquecidas em proantocianidinas oligoméricas, constituídas de monômeros, dímeros e tetrâmetros, eram as mais ativas e que as frações ricas em taninos poliméricos condensados, de massa molecular elevada, eram inativas (Abriambeloson et al., 1998). Assim, a ausência de atividade para os extra- tos de $O$. spectabilis poderia ser atribuída ao grau de polimerização das proantocianidinas presentes. Alternativamente, poderia-se considerar a presença de antagonistas das proantocianidinas naqueles extratos. Herrera et al. (1996) relataram um efeito bifásico da miricetina na resposta contrátil em anéis de aorta, com potencialização da constrição em concentrações baixas $\left(<10^{-5} \mathrm{M}\right)$ e efeito relaxante em altas concentrações $\left(>10^{-5} \mathrm{M}\right)$.

$\mathrm{O}$ extrato de caules de $O$. semiserrata foi submetido a partições seqüenciais entre solventes imiscíveis e as frações resultantes tiveram sua atividade vasodilatadora determinada. Todas as frações produziram vasodilatação significativa na concentração de $100 \mathrm{mg} / \mathrm{mL}$, obtendo-se os percentuais de vasodilatação $(n=3)$ de $92 \pm 7 \%, 85 \pm$ $5 \%$ e $68 \pm 8 \%$, respectivamente paras as frações aquosa, acetato de etila e $n$-butanólica.

Apesar da atividade significativa da fração aquosa, ela promoveu redução da resposta contrátil quando os anéis eram novamente expostos à fenilefrina. Assim, a fração EtOAc, que não apresentou este efeito, foi selecionada para fracionamento posterior. Esta foi, então, cromatografada em coluna de sílica-gel, obtendo-se 14 grupos de frações, que foram submetidos aos ensaios em anéis de aorta. A atividade concentrou-se na fração Ac12, eluída com EtOAc:MeOH (1:1), que produziu $89 \pm 19 \%$ de vasodilatação $(n=6)$. Na seqüência, Ac12 foi submetida a cromatografia em contracorrente de alta velocidade (HSCC), utilizando-se clorofórmio:metanol:água (7:13:8) como sistema de solventes, em fase normal. A fração G5, obtida ao se concentrar a fase estacionária até resíduo, ao final da corrida cromatográfica, produziu $100 \pm 5 \%$ de vasodilatação $(n=6)$, na concentração de $100 \mathrm{mg} / \mathrm{mL}$.

A fim de se avaliar a relação entre os teores de proantocinidinas e a atividade vasodilatadora, realizaramse quantificações em todas as frações ativas de $O$. semiserrata a saber, EtOAc, Ac12 e G5. Os teores totais de proantocianidinas no extrato e nas frações e os percentuais de vasodilatação correspondentes foram submetidos a análise de regressão linear (Figura 4). O gráfico obtido confirmou a dependência entre as duas variáveis $\left(r^{2}=0,9760\right)$ indicando que maiores teores de proantocianidinas implicam aumento de atividade vasodilatadora, sugerindo que compostos desta classe devem ser responsáveis pela atividade dos caules de $O$. semiserrata.

Concluindo, no presente estudo demonstrou-se a potente atividade vasodilatadora in vitro para o extrato hidroalcoólico de caules de $O$. semiserrata a qual, juntamente com a atividade inibitória da ECA in vitro, anteriormente relatada (Braga et al., 2000), apontam a espécie como fonte de substâncias bioativas, potencialmente úteis para o tratamento da hipertensão primária. Demonstrou- 


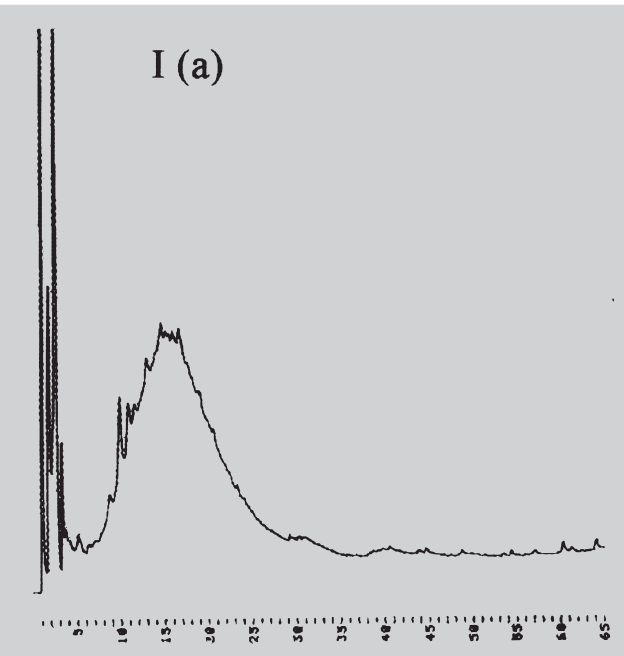

I (b)
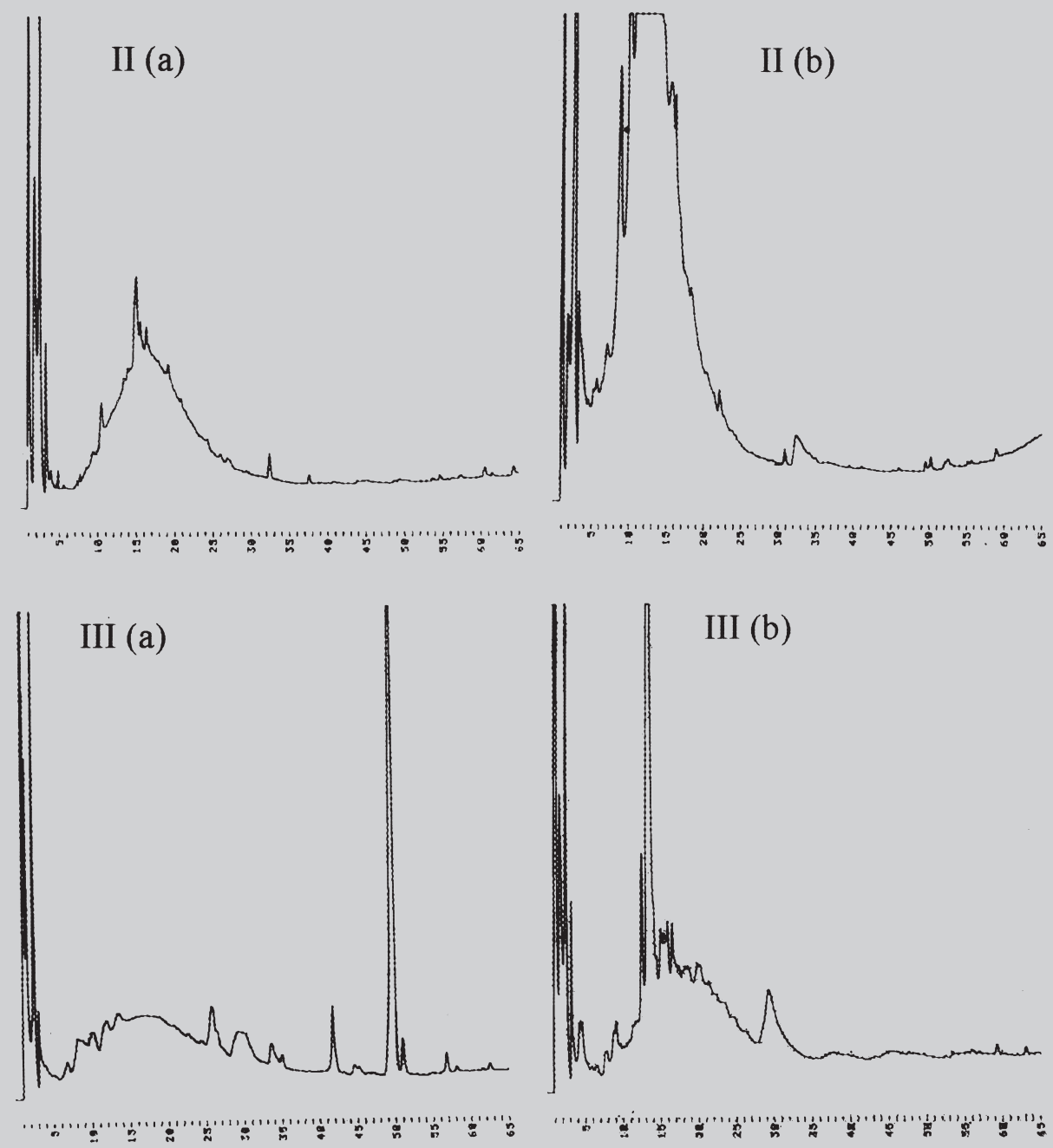

FIGURA 3 - Perfis cromatográficos, obtidos por HPLC, para extratos hidroetanólicos das espécies de Ouratea em estudo. Condições cromatográficas: vide parte experimental. (I) Ouratea castanaefolia (a; caules; b, folhas); (II) Ouratea semiserrata (a; caules; b, folhas); (III) Ouratea spectabilis (a; caules; b, folhas). 


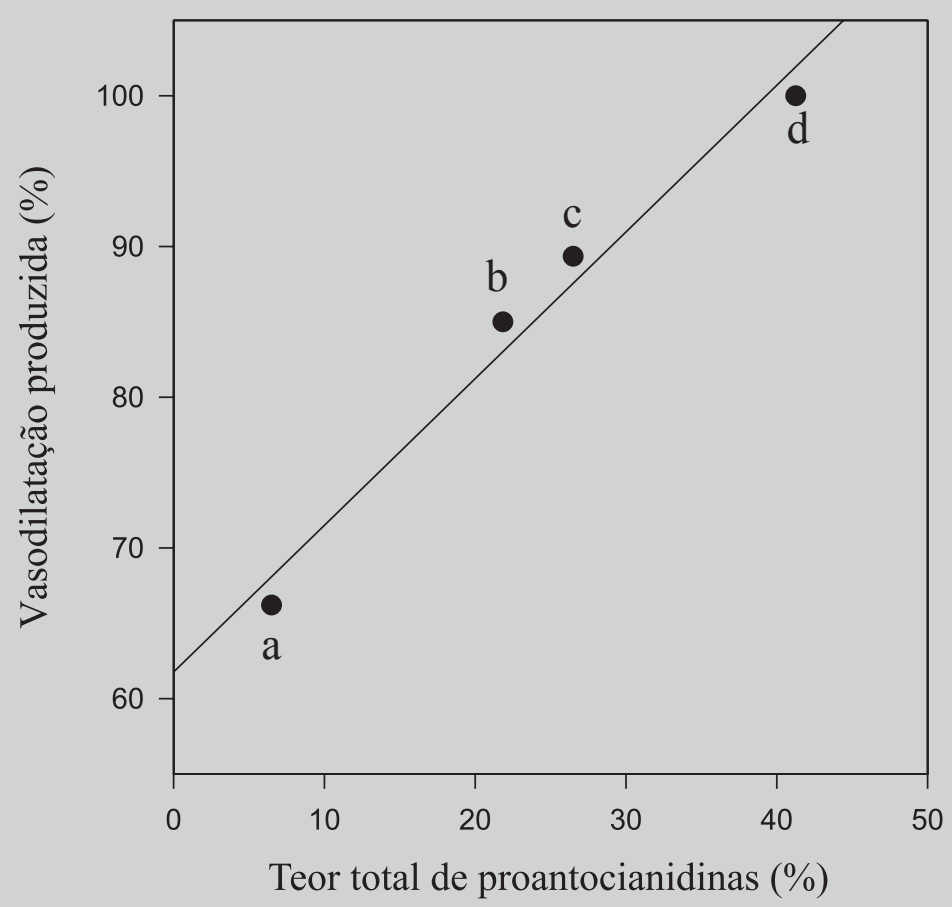

FIGURA 4 - Regressão linear entre efeito vasodilatador in vitro e teor total de proantocianidinas no extrato e frações de caules de Ouratea semiserrata. (a) Extrato hidroetanólico de caules de O. semiserrata; (b) fração acetato de etila; (c) fração Ac12; (d) fração G-5.

se, também, a dependência entre a atividade vasodilatadora e o teor total de proantocianidinas, para diferentes frações de $O$. semiserrata, sugerindo a participação de compostos desta classe na atividade observada. Estudos químicos e farmacológicos posteriores serão realizados, visando ao isolamento e à identificação do(s) composto(s) ativo(s) de $O$. semiserrata.

\section{ABSTRACT \\ In vitro vasodilator activity of Ouratea (Ochnaceae) species and fractions from Ouratea semiserrata (Mart.) engl.}

Ouratea species occur in the cerrado vegetation and some species are popularly used as tonic, astringent and antiinflammatory. In the present work, we assayed the vasodilator effects of $O$. castanaefolia, $\mathrm{O}$. spectabilis and $\mathrm{O}$. semiserrata hydroethanolic extracts in aortic rings precontracted with phenylephrine. Only $\mathrm{O}$. semiserrata stem extract (OS) produced significant vasodilatation ( $63 \pm 3$ $\%, n=6)$, at the concentration of $100 \mathrm{mg} / \mathrm{ml}$. Bioguided fractionation of OS afforded a proanthocyanidin-rich fraction that produced $100 \pm 5 \%$ vasodilatation $(n=6$; concentration of $100 \mathrm{mg} / \mathrm{ml}$ ). The total proanthocyanidin contents were assayed for $O S$ and for the bioactive fractions using a spectroscopic method. Higher proanthocyanidin contents implied in increased vasodilator activity $\left(r^{2}=0.9760\right)$, suggesting that compounds of this class may be regarded as responsible for the activity of $\mathrm{O}$. semiserrata stem extract.

UNITERMS: Ouratea semiserrata. Ouratea castanaefolia. Ouratea spectabilis. Vasodilator effect. Rat aorta. Total proanthocyanidin content.

\section{REFERÊNCIAS BIBLIOGRÁFICAS}

AMBRIAMBELOSON, E.; MAGNIER C.; HAANARCHIPOFF, G.; LOBSTEIN, A.; ANTTON, R.; BERETZ, A.; STOCLET, J. C. Natural dietary polyphenolic compounds cause endothelium-dependent vasorelaxation in rat thoracic aorta. J. Nutr., Bethesda, v.128, p.2324-2333, 1998. 
BRAGA, F. C.; WAGNER, H.; LOMBARDI, J. A.; OLIVEIRA, A. B. Screening the Brazilian flora for antihypertensive plant species for in vitro angiotensin-Iconverting enzyme inhibiting activity. Phytomedicine, Jena, v.245, p.245-50, 2000.

CORRÊA, M. P. Dicionário de plantas úteis do Brasil e das exóticas cultivadas. Rio de Janeiro: J. Di Giorgio. 1974. v. 1-6.

DELLE MONACHE, F.; D’ALBUQUERQUE, I. L.; MARINI-BETTOLO, G. B. Su di una nuova proantocianidina dimera da Ouratea. Ann. Chim., Rome, v.57, p.1364-1371, 1967.

DELLE MONACHE, F.; FERRARI, F.; D'ALBUQUERQUE, I. L.; MARINI-BETTOLO, G. B. Sterechimica delle proantocianidine da Ouratea sp. (Ochnaceae). Farmaco, Oxford, v.25, p.96-105, 1970.

FELÍCIO, J. D.; GONÇALEZ, E.; BRAGGIO, M. M.; CONSTANTINO, L.; ALBASINI, A.; LINS, A. P. Inhibition of lens aldose reductase by biflavones from Ouratea spectabilis. Planta Med., Stuttgart, v.61, p.217220, 1995.

FELÍCIO, J. D.; ROSSI, M. H.; PARK, H. R.; GONÇALEZ, E.; BRAGGIO, M. M.; DAVID, J. M.; CORDEIRO, I. Biflavonoids from Ouratea multiflora. Fitoterapia, Oxford, v.72, p.453-455, 2001.

FREITAS, M. R.; CÔRTES, S. F.; THOMAS, G.; BARBOSA FILHO, J. M. Modification of $\mathrm{Ca}^{2+}$ metabolism in the rabbit aorta as a mechanism of spasmolytic action of warifteine, a bisbenzylisoquinoline alkaloid isolated from the leaves of Cissampelos sympodialis Eichl. (Menispermaceae). J. Pharm. Pharmacol., London, v.48, p.332-336, 1996.

GRYNBERG, N. F.; MARTORELLI, R. A.; CARVALHO, M. G.; BRAZ-FILHO, R.; MOREIRA, I. C.; SANTOS, A. C. S.; ECHEVARRIA, A. Inhibition of murine tumor growth by natural biflavone and mesoionic compounds. Proc. Int. Cancer Congr. Bologna: Monduzzi Editore, v.1, p.63-66, 1994.
HERRERA, M. D.; ZARZUELO, A.; JIMÉNEZ, J.; MARHUENDA, E.; DUARTE, J. Effects of flavonoids on rat aortic smooth muscle contractility: structureactivity relationships. Gen. Pharmacol., New York, v.27, p.273-277, 1996.

HIERMANN, A.; KARTNIG, T. H.; AZZAM, S. Ein Beitrag zur quantitativen Bestimmung der Procyanidine in Crataegus. Sci. Pharm., Wien, v.54, p.331-337, 1986.

MOREIRA, I. C.; SOBRINHO, D. C.; CARVALHO, M. G.; BRAZ-FILHO, R. Isoflavanone dimers hexaspermone A, B, and C from Ouratea hexasperma. Phytochemistry, Oxford, v.35, p.1567-1572, 1994.

PACKER, L.; RIMBACH, G.; VIRGILI, F. Antioxidant activity and biologic properties of a procyanidin-rich extract from pine (Pinus maritime) bark, pycnogenol. Free Rad. Biology Med., New York, v.27, p.704-724, 1999.

PAULO, M. Q.; LIMA, E. O.; MAIA, R. F.; XAVIER FILHO, L. Atividade antimicrobiana do óleo dos frutos de Ouratea parviflora Baill (Ocnaceae).CCS, João Pessoa, v.8, p.1921, 1986.

SLISH, D. F.; UEDA, H.; ARVIGO, R.; BALICK, M. J. Ethnobotany in the search for vasoactive herbal medicines. J. Ethnopharmacol., Oxford, v.66, p.159-165, 1999.

VASQUES, C. A. R.; CÔRTES, S. F.; SILVA, S. S.; MEDEIROS, I. A. Muscarinic agonist properties of the aerial parts of Waltheria viscosissima St. Hil. (Sterculiaceae) in rats. Phytother. Res., Chichester,v.13, p.312-317, 1999.

VELANDIA, J. R.; DE CARVALHO, M. G.; BRAZFILHO, R. Novel trichloro- and tetrachloroisoflavone isolated from Ouratea semiserrata. Nat. Prod. Lett., London, v.12, p.191-198, 1998.

Recebido para publicação em 09 de agosto de 2002. 